\title{
Investigation of the Vibroacoustic Climate Inside the Buses MAN SG242 Used in Public Transport Systems
}

\author{
Z. DAMIJAN* \\ Department of Mechanics and Vibroacoustics, Faculty of Mechanical Engineering and Robotics \\ AGH University of Science and Technology, al. Mickiewicza 30, 30-059 Kraków, Poland
}

\begin{abstract}
A driver of a municipal transport bus is more liable to vibration-acoustic stimuli connected with the movement of the vehicle than a passenger. In literature on the subject noise and vibration exposures are categorised into passive (whereby passengers are exposed) and active (driver's or machine operator's exposure). Despite new technological solutions and attempts to improve the working conditions during the operation of vehicles, city bus drivers are still exposed to negative impacts of noise and vibrations, causing stress, increased fatigue and lead to numerous diseases. It is required, therefore, that the working conditions for drivers should be monitored on a regular basis. In order that they work safely, their working conditions should be as comfortable as possible, in terms of physical and psychical conditions and free from any nuisance. Therefore it seems merited to investigate the acoustic climate (i.e. acoustic phenomena caused by the sources of noise of vibrations in the function of time and space) and the working conditions during the operation of MAN SG242 vehicles, widely used in public transport systems. The following conclusions can be formulated (based on the conducted tests): the highest effective weighted values of vibration acceleration $a_{w, e q}\left(0.823 \mathrm{~m} / \mathrm{s}^{2}\right)$ (exceedance of the legitimate value) were noted in the passengers' compartment in the middles of the vehicle, the lowest- in the driver's cabin $\left(0.411 \mathrm{~m} / \mathrm{s}^{2}\right)$. In the driver's cabin, the peak noise level $L_{\text {Cpeak }}=138.7 \mathrm{~dB}$ was exceeded; as the $1 / 3$ octave analyses show, in the driver's cabin dominates low-frequency noise with the frequency from 10 to $25 \mathrm{~Hz}$ and the acoustic pressure level of about $90 \mathrm{~dB}(G)$. The research has been conducted within the framework of the author's research no 10.10.130.140 and the statuary ones no 11.11.130.119.
\end{abstract}

PACS numbers: 89.40.--a, 07.10.--h, 43.40.Lc, 07.64.+z

\section{Introduction}

All parameters discussed in this section, associated with exposure to noise at work, i.e. the maximal sound level $A$, peak sound level $C$, equivalent sound level $A$, sound exposure per a working day $(8 \mathrm{~h})$ are derivatives of the acoustic pressure.

The measure of noise exposure is the level of acoustic pressure $A, L_{p A}$ and corresponding to a balanced level of noise corrected by a frequency characteristics $A, L_{\text {Aeq, T }}$ and referred to an $8 \mathrm{~h}$ day of work acoustic noise level $L_{p}$.

Measurements data should be interpreted in the light of the regulations set forth in the Journal of Laws [29 August 2005 no 157, item 1318] having relevance to work safety in the conditions of exposure to noise and mechanic vibrations, which specify the admissible noise levels.

The impacts of vibrations might be analysed in terms of: values of parameters describing vibrations (acceleration, acceleration amplitude, frequency, exposure time), the point of transmission (whole-body or local vibrations) and personal idiosyncrasy (physical and psychical features).

First of all, vibrations impacting on people at work

* e-mail: damijan@imir.agh.edu.pl are considered harmful, provoking fatigue, drowsiness, discomfort, disturbed equilibrium. Mechanical vibrations cause stress, which affects all organs in the human body. They activate the receptors present in the skin and in other tissues, causing the reflexive response of the whole body. They lead to disturbances in the bone-joint systems, in muscles - the circulatory and nervous systems $[1-6]$.

As regards the operators' exposure, regulations relating to vibrations as nuisance should be treated as benchmarks [2]. Admissible vibration exposure levels are specified in the relevant regulations (Journal of Laws no 217 of 18 December 2002, item 1833; Journal of Laws no 212 of 28 October 2005 item 1769; Journal of Laws no 157 of 19 August 2005 item 1318; Journal of Laws no 136 of 25 July 2005 item 1145; Journal of Laws no 127 of 10 August 2002 item 1092) whereas recommendations specifying the vibration nuisance criteria can be found in the literature on the subject and in technical standards. The methods of evaluating the vibration impacts are compiled in the standard PN-91/N-03152:

- spectral method - the impacts of the exposure to vibrations are evaluated based on the effective acceleration data obtained from spectral analysis of vibration signals in $1 / 3$ octave bands, 
- weighted method, - the impacts of the exposure to vibrations are evaluated based on the effective vibration acceleration data weighted in the frequency domain, obtained from direct measurements taken with the dedicated vibration measurement devices in accordance with the standard PN-91/N-01355,

- dosimetric method - the assessment of vibration exposure is based on the equivalent weighted value of acceleration in a vibration dose, measured using a dosimeter [7-9].

In the thesis, in order to assess the human exposure to general vibrations, a weighted method (in accordance to the norm PN-91/N-03152 (measurement) has been used (Regulations Journal no 212 from Oct. 28, 2005, position 1769 and 1092 (the allowed values for vibration exposure).

The regulation by the Minister of Economy and Labour of 5 August 2005 having relevance to work safety in the conditions of noise or vibration exposure gives the threshold levels:

- local vibrations: daily exposure expressed as an energy equivalent of $8 \mathrm{~h}$ ' action of the sum of effective vectors of frequency-weighted acceleration, obtained for the three directional components $\left(a_{h w x}\right.$, $\left.a_{h w y}, a_{h w z}\right)$ - the threshold level is $2.8 \mathrm{~m} / \mathrm{s}^{2}$,

- whole-body vibrations: daily exposure expressed as an energy equivalent of $8 \mathrm{~h}$ action of the sum of effective vectors of frequency-weighted predominating acceleration, obtained for the three directional components and appropriate weighing coefficients $\left(1.4 a_{w x}, 1.4 a_{w y}, a_{w z}\right)$ - the threshold level is $0.8 \mathrm{~m} / \mathrm{s}^{2}$.

MAN AG (Maschinenfabrik Augsburg-Nürnberg Aktiengesellschaft, later - NEOPLAN Bus GmbH, and then NEOMAN) is a shared company with the headquarters in Munich. It is one of the leading companies producing trucks, buses, engines and industrial equipment, branded as MAN. The concerns employs about 33,400 workers worldwide. The first MAN truck powered by diesel engine was created in 1923. The mass production was started in the year 1925 .

In Poland the shared company called Solaris Bus \& Coach Sp. z o.o. has become the successor of the company "Neoplan Polska". In Starachowice there is a facility MAN STAR Trucks \& Buses (a former production plant of trucks "Star"), which belongs to MAN AG, and which produces components for trucks and busses and whole city busses frames. In a place called Sady near Poznań, there is located a production plant of buses, which since 1998 has been producing mainly city vehicles devoted for export. In the year 2007 in Niepołomice, there was opened a production plant of trucks of MAN trucks concern, which targeted production is 15,000 vehicles per year [10-13].

\section{Methods and procedure}

The measurement procedure was applied in accordance with the relevant standards:

- PN-EN 30326-1 - Mechanical vibrations. Laboratory method of evaluating the seat vibrations in a vehicle. Basic requirements.

- PN-91-N-01352 - Vibrations. Principles of taking measurements at work. (An equivalent of the international standard ISO 2631-1, 1997).

- PN-ISO 9612 - Acoustics. Guidelines to measurements and assessment of impacts of noise exposure at work.

- PN-EN 60651: 2002 (U) — Sound level measures. General requirements and tests.

- PN-90-S-04052 - Admissible noise level inside vehicles. Requirements and tests.

The study of the acoustic environment in buses was conducted in three places: on the driver's seat vibrations were checked by the means of a seat sensor in three axes $x, y$ and $z$; and the noise was checked with the help of a dosage meter placed in the proximity of a driver's head. In the passengers' compartment, in the middle of the vehicle and at the back of the vehicle vibrations and the noise were measured similarly. For every measurement point, signals from four channels were registered by the SVAN 948 analyzer.

Relevant correction characteristics had to be applied during the measurements:

- $W_{k}$ (for the $z$-axis) and $W_{d}$ (for the $x$ and $y$ axes) - during the vibration acceleration measurements,

- A, C, G and Linear - in measurements of audible noise.

The average time was $1 \mathrm{~s}$ for each sample.

\section{Investigation of the vibrations and acoustic climate of the MAN SG242 bus during its idle run}

Measurements were taken of:

- seat vibrations in the driver's cab during the ride,

- noise levels inside the driver's cab during the ride,

- floor vibrations in the passenger section (middle part) during the ride,

- noise levels the passenger section (middle part) during the ride, 

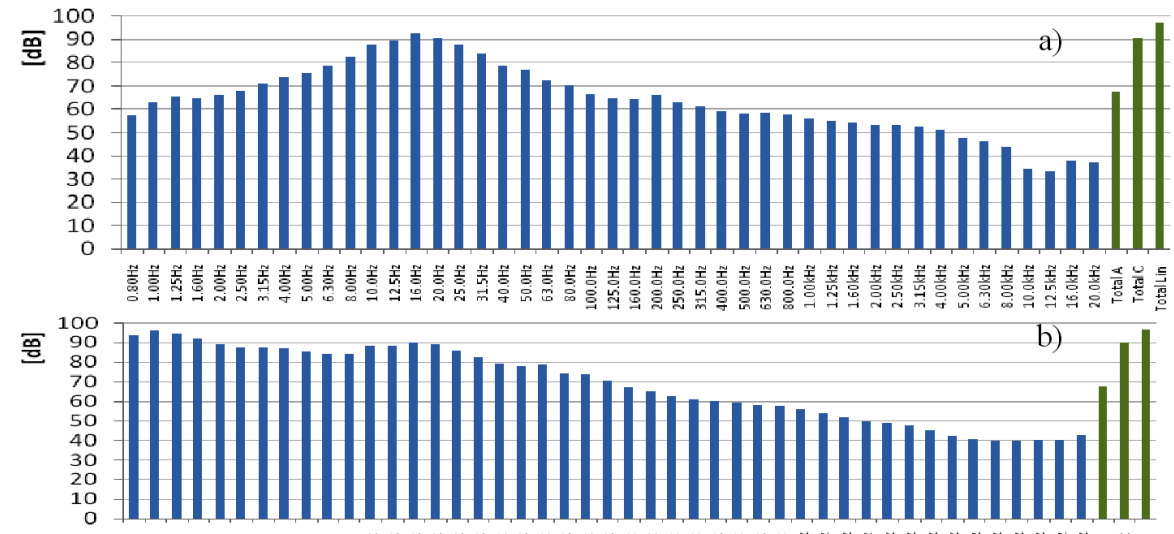

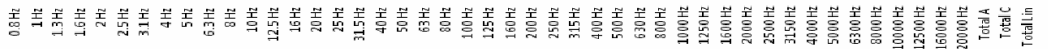
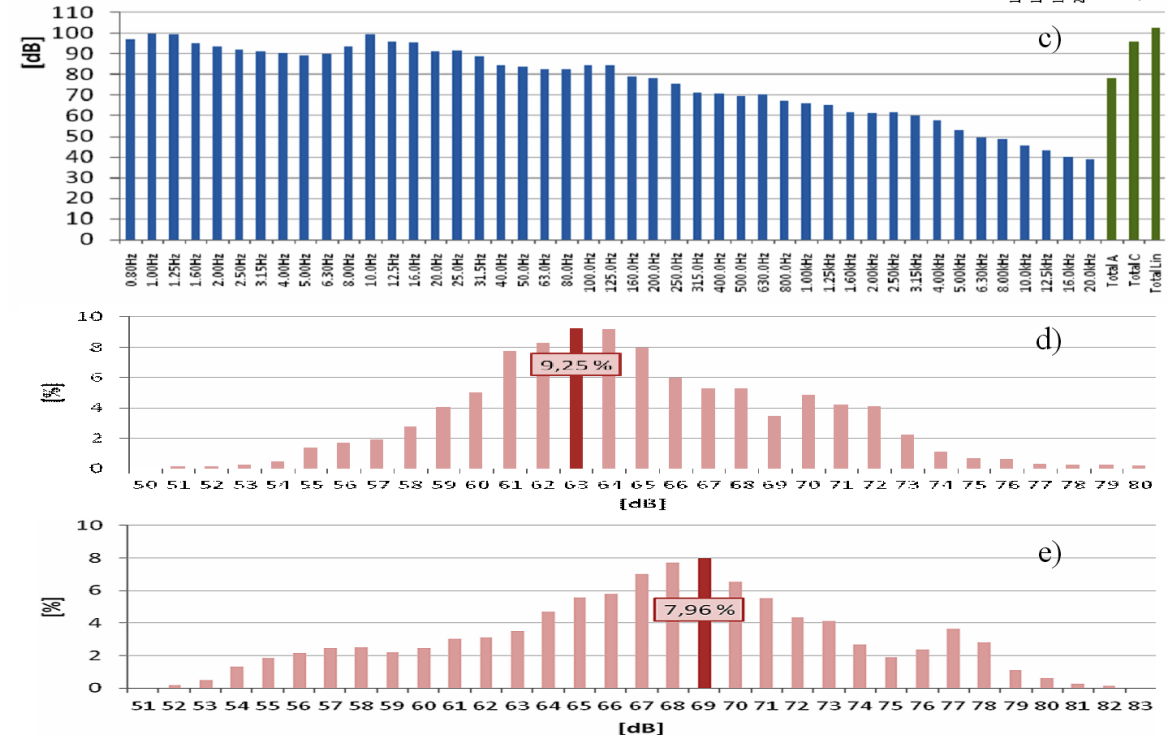

Fig. 1. (a) Noise measurements. Noise spectral analysis in $1 / 3$ oct. frequency bands (a) — driver's cabin, (b) passengers' compartment (middle), (c) - passengers' compartment (back)); (d, e) histogram of acoustic pressure level in the $((\mathrm{e})$ - driver's cabin, (f) - passengers' compartment).

- seat vibrations in the passenger section (rear part) during the ride,

- noise levels the passenger section (rear part) during the ride.

Measuring equipment (type, measuring precision category, manufacturer, manufacturer's symbol):

1. SVAN 948, I, SVANTEK, 6549,

2. SVAN 948, I, SVANTEK, 6565,

3. SVAN 945, I, SVANTEK, 6453.

The characteristics of the tested object: the age in months — 198, the mileage - 729,284 $\mathrm{km}$ (as per the day of March 28, 2008), the time of measurement 06:58-8:45; the length of the route - $54 \mathrm{~km}$, atmospheric conditions - 0.4 Centigrade, the pressure $-987 \mathrm{hPa}$; humidity - 79\%, the measuring apparatus: the driver's cabin — SVAN 948, the passengers' compartment - $2 \times$ SVAN 948, 1 × SVAN 945.

The results of vibration and noise measurements, noise spectral analysis in $1 / 3$ oct. frequency bands and histograms of acoustic pressure level, measurement data are complied in Table and Fig. 1a-e.

TABLE

The results of vibration and noise measurements. $T$ stands for the length of the sample. Bold values exceed norm.

\begin{tabular}{c|c|c|c|c|c|c}
\hline \hline Parameter & Driver & $T[\mathrm{~s}]$ & Center & $T[\mathrm{~s}]$ & Back & $T[\mathrm{~s}]$ \\
\hline$a_{w, e q}\left[\mathrm{~m} / \mathrm{s}^{2}\right]$ & 0.411 & & $\mathbf{0 . 8 2 3}$ & & 0.641 & \\
$L_{\text {Aeq }, \mathrm{T}}[\mathrm{dB}]$ & 70.0 & & 66.5 & & 78.2 & \\
$L_{\text {Amax }}[\mathrm{dB}]$ & 99.2 & 6821 & 84.7 & 6423 & 87.8 & 6180 \\
$L_{\mathrm{EX}, 8 \mathrm{~h}}[\mathrm{~dB}]$ & 63.8 & & 60.0 & & 71.5 & \\
$L_{\text {Cpeak }}[\mathrm{dB}]$ & $\mathbf{1 3 8 . 7}$ & & 124.8 & & 121.7 &
\end{tabular}




\section{Conclusions}

Basing on the conducted tests, the following conclusions can be formulated:

1. The highest effective weighted values of vibration acceleration $a_{w, e q}\left(0.823 \mathrm{~m} / \mathrm{s}^{2}\right)$ (exceedance of the legitimate value) were observed in the passengers' compartment in the middles of the vehicle, the lowest-in the driver's cabin $\left(0.411 \mathrm{~m} / \mathrm{s}^{2}\right)$.

2. In the driver's cabin, the peak noise level $L_{\text {Cpeak }}=$ $138.7 \mathrm{~dB}$ was exceeded.

3. As the $1 / 3$ octave analyses show, in the driver's cabin dominates low-frequency noise with the frequency from 10 to $25 \mathrm{~Hz}$ and the acoustic pressure level of about $90 \mathrm{~dB}(\mathrm{G})$.

4. In the passengers' compartment dominates the infrasound noise, with the frequency from 0.8 to $20 \mathrm{~Hz}$. The level of acoustic pressure is higher when compared with the middle (by about $5 \mathrm{~dB}$ ).

5. The analyses of the histograms for the range of heard frequencies show that in the driver's cabin, approximately $27 \%$ is noise at the A - level of acoustic pressure of $62-64 \mathrm{~dB}$, it is similar in the passengers' compartment - about 22\%, 68-70 dB.

6. High effective weighted values of vibration acceleration and the levels of acoustic pressure for the bus MAN SG242 may stem from the fact that for the purpose of the tests, a 16 and a half year old car with the mileage of $729.284 \mathrm{kms}$ had been chosen.

\section{References}

[1] Z. Engel, Environement protection against vibration and noise, Warszawa 1993, (in Polish).

[2] J.H. Czajka, Vibration and noise measurements on worksites in transport, Warszawa 2000, (in Polish).

[3] A. Eskandarian, R. Sayed, P. Delaigue, J. Blum, A. Mortazavi, in: Advanced Driver Fatigue Research "Final Report" 09.2003-12.2005 (2007).

[4] I. Hostens, H. Ramon, J. Sound Vibration 266, 453 (2003).

[5] A. Kaczmarska, D. Augustyńska, A. Wierzejski, Bezpieczeństwo Pracy 10, 6 (2006).

[6] J. Koton, A. Majewski, Bezpieczeństwo Pracy 7-8, 12 (2004).

[7] M. Kolich, Applied Ergonomics, 34, 177 (2003).

[8] N. Nawayseh, M.J. Griffin, J. Sound and Vibration 298, 725 (2006).

[9] O.O. Okunribido, S.J. Shimbles, M. Magnusson, M. Pope, Applied Ergonomics 38, 29 (2007).

[10] P. Eriksson, O. Friberg, Struct. Multidisc. Optim., 20, 67 (2000).

[11] S. Na, S. Lim, H.-S. Choi, M.K. Chung, Int. J. Ind. Ergon. 35, 1085 (2005).

[12] K. Tae-Hyeong, K. Young-Tae, Y. Yong-San, Int. J. Ind. Ergon. 35, 817 (2005).

[13] W.E. Falou, J. Duchêne, M. Grabisch, D. Hewson, Y. Langeron, F. Lino, Applied Ergonomics 34, 249 (2003). 